\title{
С.А. Толкачев
}

Финансовый университет при Правительстве Российской Федерации, Москва

\section{Сетевая промышленная политика}

\section{в эпоху новой индустриальной революции}

Аннотация. Затяжная мировая экономическая неопределенность, продолжающаяся уже 10 лет, свидетельствует о тектонических сдвигах в мирохозяйственном устройстве, и в частности о постепенной трансформации глобальных производственных связей. Реиндустриализация и решоринг в США вкупе с протекционистской политикой Д. Трампа подтверждают тезис о радикальной перестройке мирового индустриального ландшафта на фоне разворачивающейся новой промышленной революции. Выдвигается гипотеза о формировании новой парадигмы промышленной деятельности «глобальный дизайн - локальное производство» на базе промышленного интернета и аддитивных технологий. Сетевая организация, присущая новой парадигме, порождает новые формы промышленной политики, не опирающиеся на эффект масштаба. Сетевая промышленная политика должна учитывать, что производство и потребление перестают быть обособленными фазами в системе общественного воспроизводства, потребители способны частично выполнять функции сопроизводителя, а производители становятся потребителями краудсорсинговых услуг. Проводится критериальное сравнение сетевой промышленной политики, присущей четвертой промышленной революции, с вертикальной и горизонтальной промышленной политикой в эпоху предыдущих промышленных революций.

Ключевые слова: индустриализачия, структурные изменения, промышленная политика, инновачии, глобализачия, политика развития.

Классификация JEL: O140, O250, F630, F680.

DOI: $10.31737 / 2221-2264-2018-39-3-9$

\section{Введение}

Повестка дня на ближайшую перспективу определяется двумя важнейшими факторами. Во-первых, глобализация как парадигма существования и взаимодействия национальных экономик исчерпала себя. Во-вторых, новая промышленная революция начинает определять контуры будущей парадигмы.

К началу XXI в. основной инструмент промышленной глобализации, умножение звеньев технологической цепочки за счет процессов специализации и аутсорсинга, перестал быть главным драйвером научно-технического прогресса и конкурентного преимущества. В развитых странах активно идут процессы возврата производственных мощностей, ранее выведенных в другие страны (Маликова и др. 2015).

Феномен протекциониста Д. Трампа ${ }^{2}$, разрушителя «старой доброй» глобализации имеет глубокие политико-экономические корни - провозвестника нового этапа промышленной политики, связанного с очередной промышленной революцией.

В настоящее время, особенно после выхода в 2016 г. программной книги «Четвертая промышленная революция» К. Шваба (Schwab, 2016), тематика промышленной модернизации оказалась в центре общественного интереса. До этого господствовал термин «третья промышленная революция». Автор широко известной одноименной работы Дж. Рифкин (Rifkin, 2011) связывает ее с изменением характера и децентрализацией производства энергии.

Известный экономист Н. Рубини (Roubini, 2015) в докладе для Всемирного экономического форума в 2015 г. употребляет термин «третья промышленная революция» и полагает, что ее основными направлениями станут роботизация и внедрение автоматической техники, которые серьезным образом

\footnotetext{
${ }^{1}$ Статья выполнена при финансовой поддержке Российского фонда фундаментальных исследований (проект 18-01000877 «Проблемы конфигурации глобальной экономики ХХІ века: идея социально-экономического прогресса и возможные интерпретации»).

2 Типичный образец аналитической статьи последнего времени: «Трамп - предвестник хаоса в мировой торговле» (http://www.vestifinance.ru/articles/100013/print).
} 
повысят производительность труда. Прогресс в области программного обеспечения и 3D-печати откроет широкие перспективы развития революции в области обрабатывающей промышленности.

Однако в 2016 г. четырехэтапная периодизация побеждает трехэтапную благодаря авторитету К. Шваба и германской концепции «Индустрии 4.0», развиваемой с 2011 г., где главная роль отводится киберфизическим системам.

За последние несколько лет издано множество работ, посвященных сути цифровизации производства, промышленному интернету вещей, киберфизических системам и проч., включая работы автора этой статьи (Толкачев, 2015, 2018). Помимо тех научных сообществ, которые уже много лет исследуют воздействие новой индустриализации на промышленную политику (журналы «Экономист», «Экономическое возрождение России»), данная тема стала привлекать даже те научные школы, которые ранее отрицали необходимость активной государственной структурной политики. Например, о необходимости учета влияния новой промышленной революции на промышленную (структурную) политику было заявлено в докладе НИУ ВШЭ на ХІХ Апрельской международной конференции 2018 г. (Симачев, 2018, c. 9-10).

\section{Сетевая парадигма промышленной деятельности}

О кризисных процессах в глобальной системе мирового разделения труда, построенного по рецептам второй и третьей промышленной революции, стало известно уже давно. Например, еще в 2003 г. была опубликована статья (Imbs, Wacziarg, 2003), в которой представлены модели отраслевой концентрации и диверсификации по ряду стран. Авторам удалось установить, что по мере роста дохода в бедных странах снижается отраслевая концентрация производства и занятости в течение достаточно длительного периода развития. И только когда уровень дохода страны достигает показателя Ирландии, начинается рост концентрации производства.
Данный результат противоречит идее специализации, вытекающей из всемогущего принципа сравнительного преимущества в торговле. Ведь считается, что в результате специализации, которая должна сопровождаться повышением отраслевой концентрации, растет общая производительность экономики. Результаты, полученные Imbs \& Wacziarg, свидетельствуют о том, что экономическое развитие не обязательно основывается на принципе сравнительного преимущества. Ключевая задача состоит в освоении более широкого спектра видов деятельности, вместо того чтобы ограничиваться единственным, пусть и наиболее успешным. Данный, как и другие научные выводы, противоречащие устоявшейся логике эпохи глобализации, вывод свидетельствует о важности разработки новых подходов к определению промышленной политики, адекватных современной эпохе. В частности, освоение широкого спектра видов промышленной деятельности все более успешно достигается на основе сетевых способов взаимодействия.

О популярности сетевых форм организации бизнеса в последние годы написано огромное количество литературы. Сетевая архитектура рассматривается как эффективная альтернатива устаревшим вертикальноинтегрированным формам организации бизнес-процессов. Сети из сферы услуг проникают в промышленность. Зачатки этого видны уже сейчас - сетевые сообщества «создателей», использующих аддитивные технологии (3D-принтинг). Сообщество таких неоиндустриальных предпринимателей (электронных ремесленников), овладевающих навыками цифрового производства, получает простое, но емкое название - «создатели» (makers). В США формируется общественное движение «создателей», которое определяется Крисом Андерсоном, автором книги «Создатели: новая индустриальная револючия» (Anderson, 2012), по трем критериям, это люди:

- использующие цифровые технологии для того, чтобы проектировать и размножать новые продукты;

- делящиеся своими разработками в онлайн-сообществах; 
- использующие стандартные форматы файлов, которые могут быть присланы коммерческим фирмам в сфере производственного сервиса.

Все предшествующие модели промышленной политики исходили из необходимости развивать конкурентные преимущества производителей на основе әффекта масштаба. Однако развитие аддитивных технологий на базе промышленного интернета вещей способствует формированию новой парадигмы промышленной деятельности «глобальный дизайн - локальное производство» вместо существующей ныне противоположной парадигмы «локальный дизайн - глобальное производство».

Существующая субтрактивная парадигма «локальный дизайн - глобальное производство» (рис. 1), соответствующая пятому технологическому укладу и эпохе глобализации, базируется на глобальной цепочке производственных предприятий $(P)$ транснациональной компании, вплоть до финального сборщика $\left(P_{1}\right)$, который осуществляет поставки конечной продукции потребителям $(C)$. Подразделение разработок и дизайна $(D)$, как правило, находится в стране штабквартиры ТНК.

Идеология промышленной политики эпохи глобализации гласила: развитые страны удерживают на своей территории наиболее наукоемкие виды деятельности - НИОКР, дизайн, управление логистикой и проч., а собственно производство как второсортный вид

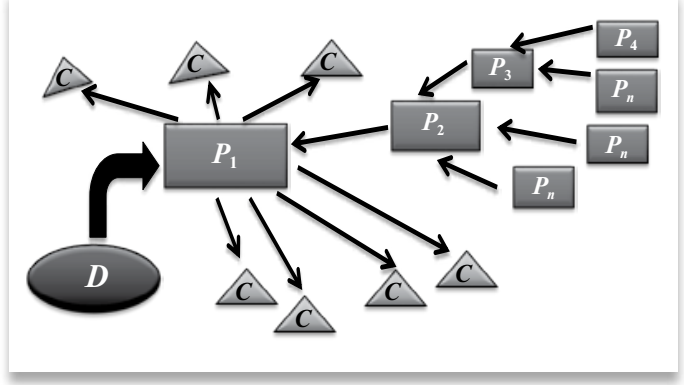

Рис. 1

Старая субтрактивная парадигма промышленной деятельности «локальный дизайн-глобальное производство» деятельности подлежит размещению на производственных площадках в развивающихся странах. ТНК добивались сокращения удельных издержек на производство, продолжая извлекать эффект масштаба за счет своего превосходства в области маркетинга и управления глобальными технологическими цепочками.

Новая аддитивная парадигма «глобальный дизайн - локальное производство», основанная на технологиях четвертой промышленной революции, разрушает основы промышленной политики, базирующейся на әффекте масштаба и системе углубления разделения труда. Новая парадигма означает глобализацию дизайна за счет развития инфокоммуникационных технологий, а сам производственный процесс, основанный на аддитивных технологиях, перестает быть сложной управленческой системой логистических цепочек поставщиков и потребителей промежуточной продукции. Новая парадигма (рис. 2) будет означать сетевую кооперацию центров дизайна $D$, каждый из которых сможет транслировать по сетям технологию производства в виде программных кодов многочисленным локализованным производителям $\left(P_{1}\right)$, которые ориентируются на конкретных потребителей $(C)$ с индивидуализированными запросами.

Чрезвычайно важно, что распространение 3D-технологий будет обеспечиваться гигантским потенциалом положительных внешних эффектов, заложенных в эту производственную парадигму. Подобно другим положительным сетевым эффектам, использо-

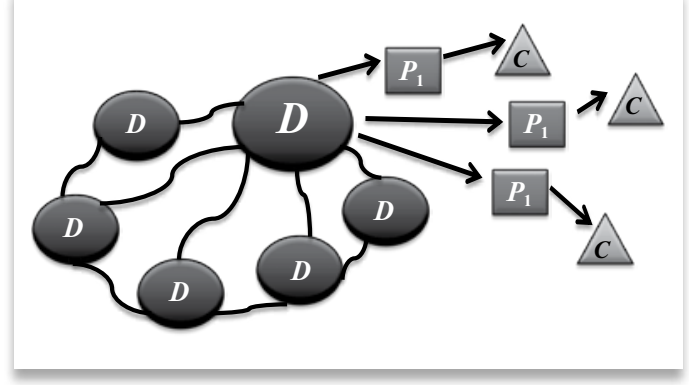

Pис. 2

Новая аддитивная парадигма промышленной деятельности «глобальный дизайн -локальное производство» 
вание 3D-принтеров будет обладать растущей отдачей по мере присоединения новых акторов к сообществу дизайнеров-маркетологов и производителей.

\section{Характеристика формирующейся сетевой промышленной политики}

В последние годы в мире происходит активное накопление новых подходов к пониманию промышленной политики (Warwick, 2013). Eе рассматривают как средство преодоления информационных әкстерналий и упрощения внешних эффектов координации (Pack, Saggi, 2012). Появляются исследования, в которых промышленную политику стали сопоставлять с эпохой постмодерна (Meyer-Stamer, 2009).

Авторитетный специалист по промышленной политике Д. Родрик в работе 10-летней давности (Rodrik, 2004) фактически предсказал сетевую траекторию трансформачии промышленной политики, когда написал, что последняя означает создание такой среды, в которой агенты частного и государственного секторов вместе решали бы проблемы производственной сферы, в которой одна сторона была бы осведомлена о возможностях и ограничениях другой. Таким образом, новую промышленную политику следует рассматривать как исследовательский процесс, в ходе которого компании и правительство узнают об основных затратах и возможностях и вовлекаются в стратегическое взаимодействие.

Сейчас накануне очередного технологического рывка, связанного с радикальным изменением основ производственного процесса (промышленный интернет вещей, переход от субтрактивного к аддитивному производству), требуются беспрецедентно высокая концентрация усилий научно-технических специалистов и предельная минимизация барьеров для технологического трансфера. Отдельные компании, какими бы ресурсами они ни обладали, какой бы поддержкой государства ни пользовались, оказываются не в состоянии решить такую масштабную задачу. Поэтому в некоторых наиболее развитых странах в настоящее время государство, наряду с использованием других инструментов промышленного стиму- лирования, активно способствует формированию инновационно-промышленных сетей, объединяющих наиболее значимые для развития критических технологий научно-исследовательские институты и промышленные компании (например, Общество Фраунхофера в Германии; Национальная сеть инноваций в обрабатывающей промышленности США (Hart, Ezell, Atkinson, 2012)).

Получившая широкую популярность в начале XXI в. книга (Княгинин, Щедровицкий, 2005) провозгласила классификацию форм промышленной политики (жесткая (вертикальная) и мягкая (горизонтальная)), причем мягкая совпадала с расцветом глобализации, что следовало из названия самой книги. Очевидно, что развитие новых (сетевых) производительных сил потребует формирования новой системы политикоэкономических отношений, стимулирующих структурные сдвиги, чем и является по сути промышленная политика. В таблице, развивая подход Княгинина-Щедровицкого, мы приводим сравнительные характеристики предшествующих и формирующегося сетевого типа промышленной политики.

Мы предлагаем соединить эпохи расцвета второй, третьей и четвертой промышленных революций с разными видами промышленной политики. Жесткая (вертикальная) промышленная политика является результатом распространения промышленных форм организации, берущих начало с полномасштабного применения конвейера в 1908 г., - вторая промышленная революция. Гигантский потенциал преобразований, заключавшийся в построении вертикально-интегрированных промышленно-логистических систем, способствовал резкому росту әффективности на основе извлечения положительного әффекта масштаба.

Переход к мягкой (горизонтальной) промышленной политике произошел вместе с распространением инфокоммуникационных технологий и автоматизированных систем управления в промышленности, - третья промышленная революция. Тотальное внедрение инфокоммуникационных технологий в управ- 
Таблица

Сравнительная характеристика вертикальной, горизонтальной и сетевой промышленных политик

\begin{tabular}{|c|c|c|c|}
\hline \multirow{2}{*}{ Характеристика } & \multicolumn{3}{|c|}{ Промышленная политика } \\
\hline & Вертикальная & Горизонтальная & Сетевая \\
\hline $\begin{array}{l}\text { Период } \\
\text { существования }\end{array}$ & $\begin{array}{l}\text { 1920-1960-е годы. } \\
\text { Вторая промышлен- } \\
\text { ная революция }\end{array}$ & $\begin{array}{l}\text { 1960-2010-е годы. } \\
\text { Третья промышлен- } \\
\text { ная революция }\end{array}$ & $\begin{array}{l}\text { 2010-е годы - ? } \\
\text { Четвертая промыш- } \\
\text { ленная революция }\end{array}$ \\
\hline $\begin{array}{l}\text { Ключевые техноло- } \\
\text { гии развития про- } \\
\text { мышленности }\end{array}$ & $\begin{array}{l}\text { Конвейер; } \\
\text { двигатель внутрен- } \\
\text { него сгорания; } \\
\text { нефтехимия }\end{array}$ & $\begin{array}{l}\text { Автоматизированные } \\
\text { системы управления }\end{array}$ & $\begin{array}{l}\text { Аддитивные техно- } \\
\text { логии, } \\
\text { промышленный } \\
\text { интернет, робототех- } \\
\text { ника }\end{array}$ \\
\hline $\begin{array}{l}\text { Новые особенности } \\
\text { промышленного про- } \\
\text { изводства }\end{array}$ & $\begin{array}{l}\text { Серийное и массовое } \\
\text { производство }\end{array}$ & $\begin{array}{l}\text { Подетальная специ- } \\
\text { ализация; } \\
\text { повышение эффек- } \\
\text { тивности управле- } \\
\text { ния производством } \\
\text { и потреблением }\end{array}$ & $\begin{array}{l}\text { Кастомизация произ- } \\
\text { водства; } \\
\text { размывание границ } \\
\text { между производством } \\
\text { и потреблением }\end{array}$ \\
\hline $\begin{array}{l}\text { Конкурентное пре- } \\
\text { имущество произво- } \\
\text { дителя }\end{array}$ & $\begin{array}{l}\text { Эффект масштаба } \\
\text { крупного машинного } \\
\text { производства }\end{array}$ & $\begin{array}{l}\text { Рост эффекта мас- } \\
\text { штаба за счет за счет } \\
\text { разделения труда } \\
\text { и специализации }\end{array}$ & $\begin{array}{l}\text { Обслуживание инди- } \\
\text { видуализированных } \\
\text { потребностей }\end{array}$ \\
\hline $\begin{array}{l}\text { Новые институты } \\
\text { промышленного раз- } \\
\text { вития }\end{array}$ & $\begin{array}{l}\text { Вертикальная инте- } \\
\text { грация и концентра- } \\
\text { ция производства }\end{array}$ & $\begin{array}{l}\text { Глобальный аутсор- } \\
\text { синг бизнес-процес- } \\
\text { сов, } \\
\text { стратегические } \\
\text { альянсы }\end{array}$ & $\begin{array}{l}\text { Сетевые структуры } \\
\text { бизнеса, науки и обра- } \\
\text { зования; } \\
\text { неформальные сети } \\
\text { производителей } \\
\text { кастомизированной } \\
\text { продукции; } \\
\text { производственный } \\
\text { краудсорсинг }\end{array}$ \\
\hline $\begin{array}{l}\text { Основное содержа- } \\
\text { ние промышленной } \\
\text { политики }\end{array}$ & $\begin{array}{l}\text { Содействие формиро- } \\
\text { ванию вертикально- } \\
\text { интегрированных } \\
\text { промышленных кор- } \\
\text { пораций }\end{array}$ & $\begin{array}{l}\text { Содействие развитию } \\
\text { аутсорсинга и специ- } \\
\text { ализации в рамках } \\
\text { глобальных цепочек } \\
\text { стоимости }\end{array}$ & $\begin{array}{l}\text { Содействие развитию } \\
\text { решоринга и локали- } \\
\text { зации производства }\end{array}$ \\
\hline
\end{tabular}

ленческую, маркетинговую, дизайнерскую и финансовую сферы привело к производственному оффшорингу и позволило до определенной поры наращивать эффективность разрастающихся глобальных цепочек стоимости. Положительный эффект масштаба продолжил определять вектор промышленной политики.
Четвертая промышленная революция формирует новый индустриальный ландшафт, частично не совместимый с универсальным принципом формирования промышленной политики, нацеленной на дальнейший рост эффекта масштаба. 


\section{Заключение}

Промышленная или структурная политика как целенаправленная совокупность инструментов воздействия государства на организацию перспективных видов экономической деятельности не может не реагировать на технологические изменения. В настоящее время на фоне кризиса глобализации становится все более очевидным исчерпание ресурсов той модели промышленной политики развитых стран, которая способствовала росту подетальной специализации и разрастанию глобальных цепочек стоимости. Новый образ промышленной политики, рождаемый в результате развития логики политико-экономической борьбы за переформатирование глобальной экономики, сочетает в себе как давно знакомые, и даже примитивные, инструменты протекционизма, так и не имеющие аналогов в истории формы поддержки сетевого предпринимательства, ориентированного на локальные рынки.

Четвертая промышленная революция, основными драйверами которой в области обрабатывающей промышленности являются промышленный интернет вещей, роботизация, аддитивные технологии, способна радикально преобразить мировой индустриальный ландшафт. Размываются границы между ранее обособленным производством и потреблением. Производственная деятельность частично станет доступна самим потребителям, а потребление с помощью краудсорсинга станет частью производственного процесса. Есть основания полагать, что положительный эффект масштаба как базовая парадигма промышленной деятельности и универсальный критерий әффективности промышленной политики может утратить свое значение в новую индустриальную эпоху. Новая сетевая промышленная политика будет нацелена не на построение сложнейших производственнологистических цепочек, а на обслуживание кастомизированных потребителей, частично вовлеченных в производственный процесс.

\section{ЛИТЕРАТУРА}

Княгинин В.Н., Щедровицкий П.Г. (2005). Промышленная политика России - кто оплатит издержки глобализации? М.: Европа.

Маликова О.И., Побываев С.А., Толкачев С.А. (2015). Энерго-сырьевые факторы и перспективы реиндустриализации экономики США / / США-Канада: экономика, политика, культура. № 9 (549). C. 3-22.

Симачев Ю.В. (2018). Структурная политика в России: новые условия и возможная повестка. Тез. докл. на XIX Апр. Междунар. науч. конф. по проблемам развития экономики и общества. Москва, 10-13 апреля. М.: Изд. дом Высшей школы экономики. С. 1-32.

Толкачев С.А. (2015). Две модели неоиндустриализации: Германия - «Индустрия 4.0», США - «Промышленный интернет» // Экономист. № 9. С. 13-23.

Толкачев С.А. (2018). Промышленная политика в эпоху цифровой трансформации экономики. Под ред. С.А. Толкачева. М.: Кнорус. С. 204.

Anderson C. (2012). Makers: the New Industrial Revolution. N.Y.: Crown Business.

Hart D.M., Ezell S.J., Atkinson R.D. (2012). Why AmericaNeedsANationalNetworkfor Manufacturing Innovation. [Электронный pecypc] // The Information Technology $\mathcal{E}$ Innovation Foundation. Washington. December 11. Режим доступа: https:// itif.org/publications /2012/12/11/ why-america-needs-national-network-manufacturing-innovation, свободный. Загл. с экрана. Яз. англ. (дата обращения: июль 2018 г.).

Imbs J., Wacziarg R. (2003). Stages of Diversification // American Economic Review. Vol. 93 (1). P. 63-86.

Meyer-Stamer J. (2009). Modern Industrial Policy or Postmodern Industrial Policies? Berlin: Friedrich Ebert Foundation. [Электронный ресурс] Режим доступа: http://www.jms-scholarship.com/fileadmin/user_files/Meyer-Stamer_modern_ or_post_modern_industrial_policy.pdf, свободный. Загл. с экрана. Яз. англ. (дата обращения: апрель 2018 г.). 
Pack H., Saggi K. (2006). The Case for Industrial Policy: A Critical Survey; Policy Research Working Paper Series from The World Bank. No. 3839. January.

Rifkin J. (2011). The Third Industrial Revolution: How Lateral Power Is Transforming Energy, the Economy, and the World. New York: Palgrave Macmillan.

Rodrik D. (2004). Industrial Policy for the Twenty-First Century. [Электронный ресурс] John H. Kennedy School of Government, Harvard University, mimeo. Режим доступа: https://www.sss.ias.edu/files / pdfs / Rodrik/Research/industrial-policy-twenty-first-century.pdf, свободный. Загл. с экрана. Яз. англ. (дата обращения: апрель 2018 г.).

Roubini N. (2015). The Third Industrial Revolution. Potential Impacts of Technology on Employment. [Электронный pecypc] Strategic Foresight: Perspectives on Global Shifts. WEF. Режим доступа: http://reports.weforum.org/global-strategic-foresight-community/nouriel-roubini-new-york-university-the-third-industrial-revolution/), свободный. Загл. с экрана. Яз. англ. (дата обращения: апрель 2018 г.).

Schwab K. (2016). The Fourth Industrial Revolution. Kindle Edition. First published January $11^{\text {th }} 2016$ by World Economic Forum.

Warwick K. (2013). Beyond Industrial Policy: Emerging Issues and New Trends. OECD Science, Technology and Industry Policy Papers No. 2. Paris: OECD Publishing.

Поступила в редакиию 22 апреля 2018 г.

\section{REFERENCES}

(with English translation or transliteration)

Anderson C. (2012). Makers: the New Industrial Revolution. N.Y.: Crown Business.

Hart D.M., Ezell S.J., Atkinson R.D. (2012). Why America Needs A National Network for Manufacturing Innovation. The Information Technology E Innovation Foundation. Washington. December 11. Available at: https:/ / itif.org/publications / 2012/12/11/ why-america-needs-national-network-manufacturing-innovation (accessed: July 2018).

Imbs J., Wacziarg R. (2003). Stages of Diversification. American Economic Review, 93 (1), 63-86.

Knyaginin V.N., Shchedrovitsky P.G. (2005). Industrial Policy of Russia: Who Will Pay the Costs of Globalization? Moscow: Europe (in Russian).

Malikova O.I., Pobivaev S.A, Tolkachev S.A. (2015). Energy and Raw Materials Factors And Prospects of the U.S. Economy Reindustrialization. USA E Canada: Economics Politics-Culture, 9 (549), 3-22 (in Russian).

Meyer-Stamer J. (2009). Modern Industrial Policy or Postmodern Industrial Policies? Berlin: Friedrich Ebert Foundation. Available at: http://www.jms-scholarship.com/fileadmin/user_files/Meyer-Stamer_modern_ or_post_modern_industrial_policy.pdf (accessed: April 2018).

Pack H., Saggi K. (2006). The Case for Industrial Policy: A Critical Survey; Policy Research Working Paper Series from The World Bank No 3839. January.

Rifkin J. (2011). The Third Industrial Revolution: How Lateral Power Is Transforming Energy, the Economy, and the World. New York: Palgrave Macmillan.

Rodrik D. (2004). Industrial Policy for the Twenty-First Century. John H. Kennedy School of Government, Harvard University, mimeo. Available at: https://www.sss. ias.edu / files / pdfs / Rodrik/Research / industrial-policy-twenty-first-century.pdf (accessed: April 2018).

Roubini N. (2015). The Third Industrial Revolution. Potential Impacts of Technology on Employment. Strategic Foresight: Perspectives on Global Shifts. WEF. Available at: http://reports.weforum.org/global-strategic-foresight-community/nouriel-roubini-new-york-university-the-third-industrial-revolution/ (accessed: April 2018).

Schwab K. (2016). The Fourth Industrial Revolution. Kindle Edition. First Published January $11^{\text {th }} 2016$ by World Economic Forum. 
Simachev Yu. (2018). Structural Changes in the Russian Economy and Structural Policy: the theses of the report on the XIX April International Academic Conference. Moscow: Higher School of Economics (in Russian).

Tolkachev S.A. (2015). Two Neoindustrialization Models: Germany - Industrie 4.0, USA Industrial Internet. Economist, 9, 13-23 (in Russian).
Tolkachev S.A. (ed.) (2018). Industrial Policy in the Age of the Digital Transformation of the Economy. Moscow: Knorus (in Russian).

Warwick K. (2013). Beyond Industrial Policy: Emerging Issues and New Trends. OECD Science, Technology and Industry Policy Papers No. 2. Paris: OECD Publishing.

Received 22.04.2018

\section{S.A. Tolkachev}

Financial University under the Government of the Russian Federation, Moscow, Russia

\section{Network Industrial Policy in the Age of the New Industrial Revolution}

Abstract. The prolonged world economic uncertainty for last 10 years, testifies to tectonic shifts in the world economic structure, and, in particular, about the gradual transformation of global production. Reindustrialization and reshoring in the US, coupled with the protectionist policy of D. Trump, confirm the thesis of a radical restructuring of the world industrial landscape on the new industrial revolution background. The article advances a hypothesis of a new industrial paradigm «global design local production» on the basis of industrial Internet and additive technologies. Network organization, inherent in the new paradigm, generates new forms of industrial development assistance. A hypothesis is proposed to stop the orientation to the "scale effect" in the conduct of a network industrial policy. Network industrial policy must take into account that production and consumption cease to be separate phases in the system of social reproduction, consumers are able to partially perform the functions of a co-productor, and producers become consumers of crowdsourcing services. A criterial comparison is made of the network industrial policy inherent in the Fourth Industrial Revolution, with vertical and horizontal industrial policies operating in the era of the previous industrial revolutions.

Keywords: industrialization, structural change, industrial policy, innovation, globalization, development policy.

JEL Classification: O140, O250, F630, F680.

DOI: $10.31737 / 2221-2264-2018-39-3-9$

А. А Яковлев

Институт анализа предприятий и рынков НИУ ВШЭ, Москва, Россия

Институт анализа предприятий и рынков НИУ ВШЭ, Москва, Россия

Институт анализа предприятий и рынков НИУ ВШЭ, Москва, Россия

\section{Новые возможности и инструменты региональной структурной политики}

Аннотация. В контексте международного опыта обсуждается участие региональных властей в реализации программ структурной трансформации. Показано, что региональные власти скорее могут увидеть ранее не раскрытые конкурентные преимущества своих территорий и воспользоваться ими, на субнациональном уровне проще обеспечить координацию и кооперацию

\footnotetext{
Данная статья подготовлена в рамках проекта «Структурные изменения в российской экономике и структурная политика», выполненного в НИУ ВШЭ в 2017-2018 гг., с частичным использованием результатов совместного проекта НИУ ВШЭ и Воронежского государственного университета «Региональная модель управления и политика раз вития отраслевых рынков в Воронежской области», выполненного в 2016-2017 гг.
} 